\title{
HOPEFULNESS, POSITIVE AND NEGATIVE EMOTIONS IN RURAL RESIDENTS WITH DRINK WATER SHORTAGE: AN IRANIAN CASE STUDY
}

\author{
Siamak Khodarahimi \\ Eghlid Branch-Islamic Azad University, Iran \\ E-mail: khodarahimi@yahoo.com \\ Heidar Deghani \\ Rural Water and Sewage Corporation of Fars Province, Iran \\ E-mail: haydardehghani@yahoo.com
}

\begin{abstract}
The purpose of this study was to examine the effects of drinking water shortage on emotions and hope in an Iranian sample, and to investigate the roles of gender, location of residence, marital status, job and the level of education on these constructs. Participants were included 1198 rural residents from two regions with and without drinking water shortage from Darab and Eghlid cities, Iran. A demographic questionnaire, the Adult Dispositional Hope Scale (ADHS), the Adult State Hope Scale (ASHS) and the Positive and Negative Affect Schedule (PANAS) were used in this study. The rural residents with drinking water shortage had higher levels of negative emotions than rural residents without drinking water shortage. However, rural residents without drink water shortage had the higher performance on positive emotions, dispositional hope and state hope than the rural residents with drink water shortage. The effects location of residence, gender, the level of education and occupation on positive and negative emotions, dispositional hope and state hope are confirmed in this sample.

Key words: demographics, dispositional and state hope, drink water shortage, positive and negative emotions.
\end{abstract}

\section{Introduction}

With the current rates of urban growth it is suggested that half the world's population would living under the water shortage in the next future. Overall, the amalgamation of climate change and population growth factors is projected to reduce the accessible water resources as a major crisis in the world. Drought is a natural disaster and a recurring feature of climate change, it can be considered as one of the most harmful and the costly natural hazards because of its negative impacts on individuals, society, physical environment and the sustainable development (Pereira, Cordery \& Iacovides, 2009). Moreover, the Middle East is the largest part of water-scarce region in the world (Beaumont, 2000; \& Roudi-Fahimi, Creel \& De Souza, 2002). Particularly, Iran is a scorched country with water surpluses on hand in only small portions of the northern and western parts (Beaumont, 1974). Water scarcity is combined by the unequal distribution of water across the different regions of the country. The Iran is a vast country with a little amount of precipitation, and overuse of many 
water sources put it into a dry and drought-prone country, and today it links up with to the arid/ semi-arid zone of Asia (Karbalaee, 2010). Authorities in the country have forced the water rationing Volume 3, 2012 in the country for dealing with the worst parchedness in three decades. The Iranian authorities had already notified that 12 million people in urban and rural areas might experience the drink water shortages (Deutsche Press Agentur, 2001). The officials are declared that the southwestern parts of Fars province facing a shortage of drink water due to the rare aridity that has dried up rivers and underground water, and this is a threat for people who live in Darab city, as well as the rural areas in these regions (Dehghani, 2011). Authorities are informed all villages in this city were experiencing serious deficits of drinkable water, and all they in these regions were counterfeit critically under the drought conditions (Dehghani, 2011).

Altogether, rainfall for the time of winter in these cities is practically reduced and water deficiency in these regions steadily is raised up in the three past years. Furthermore, the earth still was not capable of acting as a reliable source for perpetual drink water in the recent years across these regions. Specifically, the commencement of summer months brings up the problems of water shortage in these regions (Dehghani, 2011). Thereby, the drink water scant in these territories would reduce hopefulness in water shortage-affected rural residents and in turn it cause some negative emotions among rural people, and in practice this disaster might change their interests for building up a few non-conventional and novel coping styles against the drought, including desalination of groundwater, and water import projects. In sum, higher temperatures, lower rainfall and decreased an average of water resources in the aforesaid cities are the key constraints for the decline of hopefulness and amplify the negative emotions in people who are living in these regions. Thereby, the present study was purposed to investigate the effects of drink water scarcity on hopefulness and emotional status of rural residents in all villages around Darab city, the southern of Fars province.

Hope is a phenomenological and subjective construct with intrapersonal, interpersonal and situational aspects. Studies indicated that the sense of hope is beneficial for the quality of life and it might facilitate the coping process toward the adverse situations (Bird, 1998). The role of hope as a positive coping style for thinking about the adverse situations is also affirmed in an Iranian sample (Taleghani, Yekta \& Nasrabadi, 2006). According to Erickson's psychosocial theory, the genesis of intrapersonal and interpersonal hope is founded on the first stage of development when the child experiences the primary trust relationships with care providing figures. The later ego development of child is made on this original experience with hope and it influences the maintenance and development of hopefulness in life span (Farran, Herth \& Popovich, 1995; Kozak-Krueger, 1993). Jevne's model (1991) assumed that there are three factors in the subjective experience of hope: the personal, situational, and interpersonal. The personal factor is encompasses about a central core of meaning and energy. The situational factor is experiences as the predictability which is called vulnerability and risky. The interpersonal factor is a genuine caring which includes about issues of trustworthiness and comfort. Farran, Herth and Popovich (1995) reformulated a clinical definition of hope. They noted that hope can help people to maintain a rational and attentive approach toward the unpleasant life experiences (Farran, Herth \& Popovich, 1995). They used the acronym GRACT to refer to hope construct in their conceptualization. Hope is $\mathrm{G}=$ goals that motivate and stimulate, is reliant on $\mathrm{R}=$ resources, is an $\mathrm{A}=$ active procedure to ease a sense of $\mathrm{C}=$ control, and it is founded on $\mathrm{T}$ = time (Farran, Herth \& Popovich, 1995). According to Snyder's theory, hope and optimism are two parts of cognitive, emotional, and motivational endeavors which people using them toward the future, and both constructs designate a belief that future good events would prevail over the bad events (Peterson \& Seligman, 2004). Furthermore, Snyder's theory explains the emotions as indicators of hope rather than precursors of hope. Snyder, Irving and Anderson (1991) conceptualized that hope is a positive motivational condition and it involves two working mechanisms: (a) agency or the goal-directed vigor, and (b) pathways or forecast to congregate goals. According to Snyder's theory, people can choose personal accountability and cognitively, move forward with hope, and bear in mind that all humans have attained many things that were originally viewed as impossible (Snyder, 2000). Altogether, Snyder (1994) suggested that there are three components are associated with hope: 1) having the goal-oriented beliefs; 2) inventing strategies to reach the goals; and 3) being motivated to apply sufficient effort to attain the goals. Hereby, Snyder's theory of hope can subdivide into four categories: goals, pathway beliefs, agency cognitions and barriers. Goals are 
costly and uncertain anchors of Snyder's hope theory as they provide the course and an endpoint way for hopeful thinking (Snyder, 1994, 2000). Pathway thoughts refer to the routes because people like to achieve their desired goals (Snyder, 2000). Agency thoughts refer to the motivation of goal seeking because individuals have to commence the routes towards their goals. Barriers can block the realization of personal goals and in the event of a barrier individuals follow either renounce goals or to generate fresh routes (Snyder, 2000). Studies in Snyder's theory of hope indicated that goal attainment module of hope has been associated with positive emotions, whereas goal blockages are linked to the negative emotions (Diener, 1984; Snyder et al, 1996). People with high hope do not counter in the same way to the barriers like low hope individuals because they outlook the barriers as challenges to conquer and make use of their pathway thoughts to arrange an alternative route to their goals (Snyder, 1994; 2000). High hope has been found to correlate with a number of useful constructs including low levels of depression (Snyder et al, 2002). While the low hope is associated with negative emotions and a reduction in well-being (Diener, 1984).

An emotional reaction toward the environmental threats is also resembled to emotional response toward the other disasters, and it can segregate to two categories: negative and positive emotions. The negative emotions are embrace off-putting feelings like apathy, fear, blame, anger, hostility etc. The positive emotions are including constructive feelings such as action, curiosity, empathy, optimism etc. Fredrickson (1998) assumed that the evolutional nature inbuilt in different emotions settle on their adaptive outcomes in the human life. Fredrickson (1998) well known that both negative and positive emotions are crops of adaptations in the evolution. However, both negative and positive emotions are markers of mental illness and well-being, but only the positive emotions are just capture to the negative emotions in order to make the human life more enrich (Fredrickson \& Losada, 2005). Research proved that positive and negative emotions to some extent are culturally-bounded, and they are differing among cultures (Kitayama, Markus \& Kurokawa, 2000; Scollon, Diener, Oishi \& Biswas-Diener, 2004). Positive emotions are set up people to feel better about the self and others, and feelings of negative emotions by people can be deeming them into mental disorders. If positive emotions are not following by people when they encounter the natural threats then mental disorders can increase in them. Thereby, it is imperative to investigate the effects of water scarcity on hopefulness and positive and negative emotions in residents of drought-affected regions because these constructs would have implications for the human adaptation against the natural disasters.

Altogether it seems the drink water shortage has adverse influences on hope and positive and negative emotions in residents of drought-affected regions. When people are encountered to the stressful and ambiguous state like drought they would like to suppress and forget what they are feeling as a threat for their survival. Therefore, all of disasters have been recognized as events which they are containing a host of psychological manifestations and any successive intervention at local and regional levels toward them is depends on people's abilities to dealing with the natural disasters (Rivera \& Miller, 2008). Similarly, Maybank and colleagues (1995) indicated that droughts are major natural disasters for many parts of the world but their onset is slowly and it is difficult to identify. When people begin to aware of water shortage it affects their hopefulness and emotions in the negative way. Thereby, the natural disasters are similar to the traumatic events and all they can produce the elevated levels of negative emotions and low hopefulness. Unlike the traumatic events, natural disasters could resulting in the extreme destruction of property and financial loss, and in turn these affecting personal emotions and hope efforts. Zarafshani, Gorgieski and Zamani (2007) indicated that farmers from all drought-affected regions are experience major threats to their resources rather than resource loss as a consequence of drought. They indicated that resource loss is mainly related to apply of emotion-focused coping, whereas when farmers perceived threats they were inclined to use less emotion-focused coping (Zarafshani, Gorgieski \& Zamani, 2007). When people are being disastered out they feel normal emotions and hope. The emotional consequences of natural disasters have been studied extensively in the western cultures (Norris et al, 2002). Moreover, the main risk factors for adverse outcomes of the natural disasters are included more severe exposure, female gender, middle age, ethnic minority group connection, having some extra stress, preceding psychiatric troubles, and lack of psychosocial resources (Norris et al., 2002). Research indicated that hopefulness and self-efficacy as two positive factors in emotion regulations can predict the psychological outcomes of the natural disasters in affected individuals (Benight \& Bandura, 2004). Similarly, disaster stud- 
ies are suggests that the long-lasting emotional outcomes of disasters might affect by the survivors' psychological triggers. Meredith and colleagues (2011) suggested a framework for understanding Volume 3, 2012 the antecedents of psychological effects in disasters outcomes that including: restricted movement, limited resources, limited information, trauma exposure, and perceived personal and family risk. They indicated these psychological triggers cause the emotional, behavioral, and cognitive reactions following the large-scale disasters (Meredith et al., 2011). From a psychoanalytic perspective, natural disasters might be explain as the natural lost and grief phenomenon which people need to accept and adapt them for an effective adaptation (Randall, 2009).

The present study is grounded on natural disasters, hope and emotions theories (Benight \& Bandura, 2004; Farran, Herth \& Popovich, 1995; Fredrickson \& Losada, 2005; Meredith et al., 2011; Randall, 2009; Snyder, 2000; Vugt, 2009). This study is intended to examine the effects of drink water scarcity on hopefulness and emotions in the rural residents, and to explore the roles of gender, marital status, the level of education, job and the region of residence on the aforesaid constructs in this sample. The first hypothesis is that the drinking water shortage would have significant influences on hopefulness and emotions in the drought- affected rural residents. The second hypothesis is that gender, marital status, the level of education, and the region of residence would have significant effects on hopefulness and emotional status in this sample.

\section{Methodology of Research}

The present study was investigated emotions and hope dependent variables among rural residents with and without drink water shortage based on the possible roles of a few demographics factors within a survey design in an Iranian sample.

\section{Participants}

Participates were 1198 rural residents from two regions with and without drink water shortage from Darab and Eghlid cities, Fars province, Iran. Participants in group with drink water shortage were 1038 rural residents from 36 villages with drink water shortage around Darab, the southern of Fars province. Participants in group without drink water shortage were 160 rural residents from Dejkord district around Eghlid and Sarhad-e-Chahar Dange, the northern of Fars province. The means (and standard deviations) of age for males and females were $41.20(S D=7.69)$ and $43.81(S D=7.89)$ respectively. Participants were selected from all villages in two groups by the random sampling method; and they were got the psychological consultation for adaptation during the water scarce and some technological information about the drink water equipments as an incentive for their participation in the present study. This sample was recruited from all villages with more than 10 families around the aforesaid cities. After informed consent was acquired, participants completed a questionnaire containing a few sections on background information, mental health, and coping styles.

\section{Instruments}

The demographic questionnaire included items on age, gender, marital status, ethnicity, the level of education, job, number of family size, monthly income, monthly drink water usage, monthly water price, and the city and village of residence. The three inventories used were: (1) the Adult Dispositional Hope Scale (ADHS), (2) the Adult State Hope Scale (ASHS), and (3) the Positive and Negative Affect Schedule (PANAS).

Adult Dispositional Hope Scale (ADHS; Snyder et al, 1991). The ADHS measures Snyder's cognitive model of hope (Snyder, 1994; 2002; Snyder et al., 1991). The ADHS is a self-report inventory that contains 12 items. Participants respond to each item using an 8-point scale ranging from definitely false to definitely true and the scale takes only a few minutes to complete. This scale taps into dispositional or trait hope in adults aged over 15 years (Snyder et al., 1991). The ADHS has demonstrated relatively good levels of validity when it used in a number of different populations including undergraduates, patients seeking psychological treatment and war veterans who suffer from post traumatic stress disorder (Lopez, Ciarlelli, Coffman, Stone \& Wyatt, 2000; Snyder et 
al., 1991). The ADHS has demonstrated extremely good levels of reliability with Snyder and colleagues (1991) reporting Cronbach alphas of 0.74 to 0.84 for overall hope, 0.71 to 0.76 for agency thoughts and 0.63 to 0.80 for pathway thoughts in student and clinical populations. Further evidence to support the reliability of this scale is demonstrated by the test-retest statistics, which Snyder and colleagues (1991) reports as being 0.80 or above for time periods of up to 10 weeks when sampling student populations.

The Adult State Hope Scale (ASHS, Lopez et al., 2000). The ASHS is an efficient tool for measurement of goal directed thinking in a given moment or situation. The ASHS is responsive to events in the lives of people. This scale is a 6-item self report inventory that is designed to tap into state hope in adults. Items are scored using an 8 point Likert scale (Snyder et al., 1996). The authors found Cronbach alphas of 0.79 to 0.95 for the overall ASHS, 0.79 to 0.95 for the agency sub scale and 0.59 to 0.93 for the pathway subscale (Lopez et al., 2000). Furthermore they found test-retest correlations of between 0.48 and 0.93 when comparing any two days in a month long study. Lopez and colleagues (2000) indicated that the ASHS were positively correlated with the State Self Esteem Scale (SSES; Heatherton \& Polivy, 1991) and the PANAS (Watson, Clark \& Tellegen, 1988).

Positive and Negative Affect Schedule (PANAS; Watson, Clark \& Tellegen, 1988). The PANAS has 20 items that include a positive affect (PANAS-P; 10 items) and a negative affect (PANAS-N; 10 items). Items from the PANAS-P are interested, excited, strong, enthusiastic, proud, alert, inspired, determined, attentive, and active. Items from the PANAS-N include distressed, upset, hostile, irritable, scared, jittery, afraid, ashamed, guilty, and nervous. The PANAS was developed to be a brief measure of positive and negative affect in undergraduate students and adult populations. Each item is rated on a 5-point Likert scale ranging from 1 (very slightly or not at all) to 5 (very much or extremely). There has been considerable support for the construct validity of the PANAS. Furthermore, estimates of internal consistency have been found to range from 0.86 to 0.90 for the positive affect scale, and from 0.84 to 0.97 for the negative affect scale (Chorpita, Daleiden, Moffitt, Yim \& Umemoto, 2000; Watson, Clark \& Tellegen, 1988). The concurrent validity of the PANAS was examined to the Satisfaction with Emotion Regulation Questionnaire (ERQ; Gross \& John, 2003) that supporting the construct validity of the PANAS. The PANAS, PANAS-N and PANAS-P reliability using Cronbach's alpha internal consistency in the present study was $0.90,0.88$, and 0.86 respectively.

\section{Results of Research}

To examine the first hypothesis eight ANOVAs were conducted to evaluate differences between the rural residents with drink water shortage, rural residents without drink water shortage and the total sample in their positive and negative emotions, dispositional hope and state hope. Findings showed significant differences between these groups, and rural residents with drink water shortage have the highest levels of negative emotions than other groups. However, rural residents without drink water shortage have the highest performance on positive emotions, dispositional hope and state hope than the rural residents with drink water shortage (Table 1).

Table 1. The Effect of Drink Water Shortage on Positive and Negative Emotions, Dispositional Hope, and State Hope.

\begin{tabular}{|c|c|c|c|c|c|c|c|c|}
\hline \multirow{3}{*}{ Dependents } & \multicolumn{6}{|c|}{ Groups } & \multirow{3}{*}{$F$} & \multirow{3}{*}{$p$} \\
\hline & \multicolumn{2}{|c|}{ Drought-affected } & \multicolumn{2}{|c|}{ Non drought Affected } & \multicolumn{2}{|c|}{ Total } & & \\
\hline & M & SD & M & SD & M & SD & & \\
\hline Positive emotions & 18.70 & 2.15 & 21.27 & 6.46 & 20.92 & 6.12 & 24.89 & 0.0001 \\
\hline Negative emotions & 20.80 & .87 & 19.14 & 4.63 & 19.37 & 4.36 & 20.12 & 0.0001 \\
\hline Agency & 13.42 & 6.03 & 23.50 & .92 & 14.77 & 6.58 & 444.12 & 0.0001 \\
\hline Pathway & 13.03 & 5.12 & 26.40 & 3.67 & 14.82 & 6.73 & 543.05 & 0.0001 \\
\hline
\end{tabular}




\begin{tabular}{|c|c|c|c|c|c|c|c|c|}
\hline \multirow{3}{*}{ Dependents } & \multicolumn{6}{|c|}{ Groups } & \multirow{3}{*}{$\mathbf{F}$} & \multirow{3}{*}{$p$} \\
\hline & \multicolumn{2}{|c|}{ Drought-affected } & \multicolumn{2}{|c|}{ Non drought Affected } & \multicolumn{2}{|c|}{ Total } & & \\
\hline & M & SD & M & SD & M & SD & & \\
\hline Dispositional hope & 26.46 & 11.01 & 49.90 & 4.56 & 29.60 & 13.09 & 706.04 & 0.0001 \\
\hline Agency & 10.03 & 5.32 & 19.80 & 2.75 & 11.34 & 6.05 & 515.74 & 0.0001 \\
\hline Pathway & 9.79 & 5.27 & 19.80 & 2.75 & 11.13 & 6.05 & 551.91 & 0.0001 \\
\hline State hope & 19.83 & 10.39 & 39.60 & 5.51 & 22.47 & 11.95 & 554.40 & 0.0001 \\
\hline
\end{tabular}

The second hypothesis is that gender, marital status, the level of education, and the region of residence would have significant effects on hopefulness and emotional status in this sample. To investigate the possible differences for independent variables, a multivariate analysis of variance (MANOVA) conducted by gender, marital status, the level of education, the location of residence and their interactions as independents and positive and negative emotions, dispositional hope and state hope as dependent variables. This analysis was included 599 males and 599 females. This analysis was involved 1165 married and 33 single individuals. The level of education of this sample was ranged from without literacy $(\mathrm{N}=394)$, elementary $(\mathrm{N}=565)$, guidance $(\mathrm{N}=86)$, high school $(\mathrm{N}=105)$, undergraduate $(\mathrm{N}=28)$ and postgraduate $(\mathrm{N}=18)$ levels. The job classification in this sample was included housewife $(\mathrm{N}=534)$, university student $(\mathrm{N}=25)$, workless $(\mathrm{N}=92)$, farmer $(\mathrm{N}=448)$, shopkeeper $(\mathrm{N}=27)$ and governmental employee $(\mathrm{N}=72)$ categories. An overall multivariate effect found for location of residence (Wilks' $\mathrm{k}=0.493 ; \mathrm{F}(6,1)=1.99 ; \mathrm{p}<0.0001 ; \mathrm{Eta}=0.50$ ), gender (Wilks' $\mathrm{k}$ $=0.950 ; \mathrm{F}(6,1)=10.17 ; \mathrm{p}<0.0001 ; \mathrm{Eta}=0.05)$, marital status (Wilks' $\mathrm{k}=0.980 ; \mathrm{F}(12,2)=1.33$; $\mathrm{p}<0.06$ ), the level of education (Wilks' $\mathrm{k}=0.579 ; \mathrm{F}(42,5)=7.88 ; \mathrm{p}<0.0001 ; \mathrm{Eta}=0.04$ ) and job (Wilks' $\mathrm{k}=0.868 ; \mathrm{F}(18,3)=6.62 ; \mathrm{p}<0.0001 ; \mathrm{Eta}=0.03$ ) variables. Also, this analysis is rejected the interactive effects for all independents on dependents variables (Table 2). Posteriori following test for group differences in gender by the Duncan test indicated that males have significant higher dispositional and state hope than females but they don't have significant differences in positive and negative emotions. Moreover, the Duncan test indicated that individuals with undergraduate level of education and over have significant higher positive emotions, dispositional and state hope than individuals with high school diploma and lower. Also, based on the posteriori following test there are not significant among individuals with different levels of education in negative emotions. Additionally, the Duncan test showed that individuals with governmental employee have significant higher positive emotions, dispositional and state hope that individuals who are worker, farmer, housewife, workless and shopkeeper. Finally, people with non-governmental jobs have significant higher negative emotions than individuals with the governmental jobholder.

Table 2. Tests of Between Subjects Effects for Demographics Differences in Dependents Variables.

\begin{tabular}{clccc}
\hline Independents & Dependents & $\mathbf{F}$ & $\mathbf{p}$ & Eta \\
\hline \multirow{5}{*}{ Location of residence } & Positive emotions & 12.78 & 0.0001 & 0.01 \\
& Negative emotions & 13.41 & 0.0001 & 0.01 \\
& Agency & 333.71 & 0.0001 & 0.22 \\
& Pathway & 724.87 & 0.0001 & 0.38 \\
& Dispositional hope & 521.52 & 0.0001 & 0.30 \\
& Agency & 375.56 & 0.0001 & 0.24 \\
& Pathway & 435.42 & 0.0001 & 0.27 \\
& State hope & 422.00 & 0.0001 & 0.26 \\
\hline
\end{tabular}




\begin{tabular}{|c|c|c|c|c|}
\hline Independents & Dependents & $F$ & $p$ & Eta \\
\hline \multirow{8}{*}{ Gender } & Positive emotions & 0.01 & 0.97 & \\
\hline & Negative emotions & 1.77 & 0.18 & \\
\hline & Agency & 5.24 & 0.02 & 0.004 \\
\hline & Pathway & 5.28 & 0.02 & 0.004 \\
\hline & Dispositional hope & 5.50 & 0.01 & 0.005 \\
\hline & Agency & 11.01 & 0.001 & 0.009 \\
\hline & Pathway & 28.18 & 0.0001 & 0.023 \\
\hline & State hope & 19.27 & 0.0001 & 0.016 \\
\hline \multirow{8}{*}{ Marital status } & Positive emotions & 0.66 & 0.51 & \\
\hline & Negative emotions & 1.64 & 0.19 & \\
\hline & Agency & 2.10 & 0.12 & \\
\hline & Pathway & 0.69 & 0.49 & \\
\hline & Dispositional hope & 1.39 & 0.24 & \\
\hline & Agency & 0.12 & 0.88 & \\
\hline & Pathway & 0.63 & 0.53 & \\
\hline & State hope & 0.31 & 0.73 & \\
\hline \multirow{8}{*}{ Level of education } & Positive emotions & 3.36 & 0.001 & 0.02 \\
\hline & Negative emotions & 1.18 & 0.30 & \\
\hline & Agency & 13.23 & 0.0001 & 0.07 \\
\hline & Pathway & 11.96 & 0.0001 & 0.06 \\
\hline & Dispositional hope & 12.97 & 0.0001 & 0.07 \\
\hline & Agency & 12.28 & 0.0001 & 0.06 \\
\hline & Pathway & 14.09 & 0.0001 & 0.07 \\
\hline & State hope & 13.65 & 0.0001 & 0.07 \\
\hline \multirow{8}{*}{ Job } & Positive emotions & 4.22 & 0.001 & 0.01 \\
\hline & Negative emotions & 6.22 & 0.0001 & 0.02 \\
\hline & Agency & 3.15 & 0.008 & 0.01 \\
\hline & Pathway & 2.53 & 0.02 & 0.01 \\
\hline & Dispositional hope & 2.89 & 0.01 & 0.01 \\
\hline & Agency & 3.30 & 0.006 & 0.01 \\
\hline & Pathway & 6.30 & 0.0001 & 0.02 \\
\hline & State hope & 4.24 & 0.001 & 0.01 \\
\hline
\end{tabular}

\section{Discussion}

The results from this study regarding the first hypothesis demonstrated that rural residents with drink water shortage had the higher levels of negative emotions than rural residents without drink water shortage. However, rural residents without drink water shortage had the higher performance on positive emotions, dispositional hope and state hope than the rural residents with drink water shortage. Additionally, rural residents without drink water shortage had the significant higher performance on agency and pathways subscales of dispositional and state hope than rural residents with drink water shortage. These findings are congruent with the adverse impacts on natural disasters like drought on human well-being, and they are in line with predictions of disasters outcomes on the human functioning which was supported in the previous literature (Benight $\&$ Bandura, 2004; Maybank et al., 1995; Meredith et al., 2011; Norris et al., 2002; Pereira, Cordery \& Iacovides, 2009; Randall, 2009; Rivera \& Miller, 2008; Zarafshani, Gorgieski \& Zamani, 2007). Additionally the effects of drink water shortage on increasing of negative emotions are in streak with assumptions from emotions theories (Fredrickson, 1998; Fredrickson \& Losada, 2005). It seems drink water-shortage can produce a high negative emotional reactivity against this natural threat and in turn the sense of death and life-ending in people who are experiencing this adverse environmental situation for a long-time. When the water shortage is resulting from the climate change such as the drought, it will be appear slowly but individuals can sense its presence in their everyday lives. Perhaps this process is similar to a chronic and killing disease which patient to expect the death in any times. Obviously, 
this type of disaster can predispose the person for an unexpected destruction and die which eventually it resulting to overcoming of negative emotions and losing of hopefulness. In fact, drink water

shortage is an alarm about the natural resources expire that can triggers the existential anxiety from die in human beings. Otherwise, the human response to this survival threading disaster is alike the grief and morning (Randall, 2009). This study is speculated a three stage model for encountering toward the drought a natural disaster. When people are encounter natural disaster they initially might show several negative emotions such anger, stress, denial, self-deception, illusionary hope, sense of hopelessness etc. In the second phase, they would attempt to accept natural disaster and they want to find some logical and rational solutions for their adaptation against it. The third stage is called redemption from disaster. Therefore, only people with positive emotions, optimism, hopefulness, and psychological resources could turn up to the final stage. Also, these findings about the roles of drink water shortage on reduction of dispositional and state hopes and their subscales are consistent with prediction in hope theories (Farran, Herth \& Popovich, 1995; Jevne, 1991; Peterson \& Seligman, 2004; Snyder, 2000, 1994; Snyder, Irving \& Anderson, 1991). Thereby, both dispositional and state hopes and their factors can influences by life-threatening disasters like drink water shortage.

The results from this study regarding the second hypothesis demonstrated that the effects location of residence, gender, the level of education and occupation on positive and negative emotions, dispositional hope and state hope in this sample. This study indicated that males had the significant higher dispositional and state hope than females but they didn't have significant differences in positive and negative emotions. Moreover, individuals with undergraduate level of education and over had the significant higher positive emotions, dispositional and state hope than individuals with lower levels of education. Additionally, individuals who are working in governmental jobs had the significant higher positive emotions, dispositional and state hope that individuals who have nongovernmental occupations like laboring, farming, housewife, shopkeeper, and workless. Finally, people with non-governmental jobs had the significant higher negative emotions than individuals with the governmental jobholder. Therefore, the degree to which the drink water crisis influences individuals is depending on variables such as gender, job, and education. These findings are congruent with previous studies which supported the roles of demographics such as gender and the level of education in post traumatic stress disorder (PTSD) and preparedness behavior due to the natural disasters (Pynoos et al., 1998; Russell, Goltz \& Bourque, 1995). According to the psychological stress and cognitive appraisal theory it would expect gender, job and the level of education have major roles when people are encountering the natural disasters. This theory focuses stress is a reciprocal process; the environment produces stressors, and the individual looks for ways to deal with these. This theory focuses attention on the way that people cope with disasters through their personal and resources including skills and behavioral repertoire (Lazarus, 1999; 1993). Since people act toward things on the basis of the appraisals and meanings they attribute to them; these meanings are derived through their backgrounds; and these appraisals are controlled and modified through an interpretive and cognitive process which people use to cope with disasters that they are encountered.

\section{Conclusion}

The present study adds to the psychology of natural disasters because of the exploration of drink water shortage in positive and negative emotions, dispositional hope and state hope in the rural residents, and the understanding the roles of gender, occupation and the level of education on aforesaid constructs in an Iranian sample. However, the present study is limited because of its relying on the survey method and self-rating measures. The prospective investigations can apply the longitudinal designs for this objective. Also, future studies could to examine the roles of cultural contexts on these constructs in cross-cultural studies and in different types of natural studies.

\section{Acknowledgements}

This research was supported by the Rural Water and Swage Corporation of Fars Province (RWSCFP), Shiraz, Iran. 


\section{References}

Beaumont, P. (2000). The quest for water efficiency - restructuring of water use in the Middle East. Water, Air \& Soil Pollution, 123 (1\&4), 551-564.

Beaumont, P. (1974). Water resources development in Iran. The Geographical Journal, 143 (3), 418-431.

Benight, C. C., \& Bandura, A. (2004). Social cognitive theory of posttraumatic recovery: The role perceived self-efficacy. Behaviour Research and Therapy, 42, 1129-1148.

Bird, B. S. (1998). C.R. Snyder's research on self-handicapping, excusing and hope: Overview of therapeutic applications, $\mathrm{PhD}$ Dissertation, Biola University.

Chorpita, B. F., Daleiden, E. L., Moffitt, C., Yim, L., \& Umemoto, L. A. (2000). Assessment of tripartite factors of emotion in children and adolescents I: Structural validity and normative data of an affect and arousal scale. Journal of Psychopathology and Behavioral Assessment, 22, 141-160.

Deghani, H. (2011). [The drinking water shortage in Zarindasht and Darab cities, the southwestern parts of Fars province]. The Rural Water and Swage Corporation of Fars Province (RWSCFP), Shiraz.

Deutsche Press Agentur. (2001). Water shortage threatens Iran. Retrieved 12 September 2011.

Diener, E. (1984). Subjective well-being. Psychological Bulletin, 95, 542-575.

Farran, C. J., Herth, K. A., \& Popovich, J. M. (1995). Hope and hopelessness: Critical clinical constructs. California Sage Publications.

Fredrickson, B. L. (1998). What good are positive emotions? Review of General Psychology, 2, 300-319.

Fredrickson, B. L., \& Losada, M. (2005). Positive affect and the complex dynamics of human flourishing. American Psychologist, 60 (7), 678-686.

Gross, J. J., \& John, O. P. (2003). Individual differences in two emotion regulation processes: Implications for affect, relationships, and well-being. Journal of Personality and Social Psychology, 85 (2), 348-362.

Heatherton, T. F., \& Polivy, J. (1991). Development and validation of a scale for measuring state self-esteem. Journal of Personality and Social Psychology, 60, 895-910.

Jevne, R. F. (1991). It all begins with hope. CA: LuraMedia.

Karbalaee, F. (2010). Water crisis in Iran. Paper presented at the 2010 International Conference on Chemistry and Chemical Engineering, Kyoto, Japan.

Kitayama, S., Markus, H. R., \& Kurokawa, M. (2000). Culture, emotion, and well-being: Good feelings in Japan and the United States. Cognition and Emotion, 14, 93-124.

Kozak-Krueger, M. R. (1993). Toward a better understanding of hope Master, University of Alberta, Canada.

Lazarus, R. S. (1999). Stress and emotion: A new synthesis. Springer Publishing Company. USA.

Lazarus, R. S, (1993). Coping theory and research: Past, present, and future. Psychosomatic Medicine, 55, 234-247.

Lopez, S. J., Ciarlelli, R., Coffman, L., Stone, M., \& Wyatt, L. (2000). Diagnosing for strengths: On measuring hope building blocks. In C. R. Snyder (Ed.), Handbook of hope theory, measures and applications (pp. 57-85). San Diego: Academic Press.

Maybank, J., Bonsai, B., Jones, K., Lawford, R., O’Brien, E. G., Ripley, E. A., \& Wheaton, E. (1995). Drought as a natural disaster. Atmosphere-Ocean, 32 (2), 195-222.

Meredith, L. S., Eisenman, D. P., Tanielian, T., Taylor, S. L., Basurto-Davila, R., Zazzali, J., Diamond, D., Cienfuegos, B., \& Shields, S. (2011). Prioritizing psychological consequences for disaster preparedness and response: A framework for addressing the emotional, behavioral, and cognitive effects of patient surge in large-scale disasters. Disaster Medicine and Public Health Preparedness, 5 (1), 73-80.

Norris, F. H., Friedman, M. J., \& Watson, P. J., Byrne, C. M., Diaz, E., \& Kaniasty, K. (2002). 60,000 disaster victims speak: Part I. An empirical review of the empirical literature, 1981-2001. Psychiatry: Interpersonal and Biological Processes, 65 (3), 207-239.

Pereira, L. S., Cordery, I., \& Iacovides, I. (2009). Coping with water scarcity: Addressing the challenges. Dordrecht, The Netherlands: Springer. 
Peterson, C. S., Seligman, M. E. P. (2004). Character strengths and virtues. England: Oxford University Press.

Pynoos, R. S., Goenjian, A. K., Karakashian, M., Tashjian, M., Manjikian, R., Manoukian, G., Steinberg, A. M., \& Fairbanks, L. A. (1993). Post-traumatic stress reactions in children after the 1988 Armenian earthquake. British Journal of Psychiatry, 163, 239-247.

Rivera, J. D., \& Miller, D.S. (2008). Disaster vulnerability education: A new focus on disaster education across the curriculum. Journal of Applied Security Research, 4 (1\&2), 60-67.

Randall, S. (2009). Loss and climate change: The cost of parallel narratives. Ecopsychology, 1 (3), 118-129.

Roudi-Fahimi, F., Creel, L., \& De Souza, R. M. (2002). Population and water scarcity in the Middle East and North Africa. Population Reference Bureau, 1-8.

Russell, L. A., Goltz, J. D., and Bourque, L. B. (1995). Preparedness and hazard mitigation actions before and after two earthquakes. Environment and Behavior, 27 (6), 744-770.

Scollon, C. N., Diener, E., Oishi, S, \& Biswas-Diener, R. (2004). Emotions across cultures and methods. Journal of Cross-Cultural Psychology, 35, 304-326.

Snyder, C. R. (2000). Handbook of hope: Theory, measures, and applications. CA: Academic Press.

Snyder, C. R. (1994). The psychology of hope: You can get there from here. NY: Free Press.

Snyder, C. R., Irving, L. M., \& Anderson, J. R. (1991). Hope and health: Measuring the will and the ways. In C. R. Snyder (Ed.), The handbook of social and clinical psychology: The health perspective (pp. 285307). NY: Pergamon Press.

Snyder, C. R., Shorey, H. S., Cheavens, J., Pulvers, K. M., Adams, V. H., \& Wiklund, C. (2002). Hope and academic success in college. Journal of Educational Psychology, 94 (4), 820-826.

Snyder, C. R., Sympson, S. C., Ybasco, F. C., Borders, T. F., Babyak, M. A., \& Higgins, R. L. (1996). Development and validation of the state hope scale. Personality and Social Psychology Bulletin, 70 (2), 321-335.

Taleghani, F., Yekta, Z. P., \& Nasrabadi, A. N. (2006). Coping with breast cancer in newly diagnosed Iranian women. Journal of Advanced Nursing, 54 (3), 265-272.

Vugt, M. V. (2009). Averting the tragedy of the commons : Using social psychological science to protect the environment. Current Directions in Psychological Science, 18 (3), 169-173

Watson, D., Clark, L. A., \& Tellegen, A. (1988). Development and validation of brief measures of positive and negative affect: The PANAS scales. Journal of Personality and Social Psychology, 54, 1063-1070.

Zarafshani, K., Gorgieski, M. J., \& Zamani, G. H. (2007). Dealing with drought: A comparison of perceptions and coping strategies of Iranian farmers from regions with different drought intensities. The Journal of Agricultural Education and Extension, 13 (1), 69-80.

Advised by Jan Lašek, University of Hradec Kralove, Czech Republic 